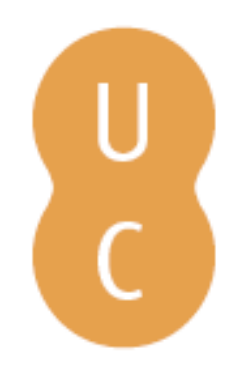

\title{
nommalina
}

\section{Hispani omnes sumus? os nacionalismos de André de Resende e Bartolomeu de} Albornoz

\author{
Autor(es): $\quad$ Pereira, Virgínia Soares
}

Publicado por: Imprensa da Universidade de Coimbra

URL

persistente: URI:http://hdl.handle.net/10316.2/38960

DOI: $\quad$ DOI:http://dx.doi.org/10.14195/978-989-26-0395-7_14

Accessed : $\quad$ 26-Apr-2023 11:41:42

A navegação consulta e descarregamento dos títulos inseridos nas Bibliotecas Digitais UC Digitalis, UC Pombalina e UC Impactum, pressupõem a aceitação plena e sem reservas dos Termos e Condições de Uso destas Bibliotecas Digitais, disponíveis em https://digitalis.uc.pt/pt-pt/termos.

Conforme exposto nos referidos Termos e Condições de Uso, o descarregamento de títulos de acesso restrito requer uma licença válida de autorização devendo o utilizador aceder ao(s) documento(s) a partir de um endereço de IP da instituição detentora da supramencionada licença.

Ao utilizador é apenas permitido o descarregamento para uso pessoal, pelo que o emprego do(s) título(s) descarregado(s) para outro fim, designadamente comercial, carece de autorização do respetivo autor ou editor da obra.

Na medida em que todas as obras da UC Digitalis se encontram protegidas pelo Código do Direito de Autor e Direitos Conexos e demais legislação aplicável, toda a cópia, parcial ou total, deste documento, nos casos em que é legalmente admitida, deverá conter ou fazer-se acompanhar por este aviso.

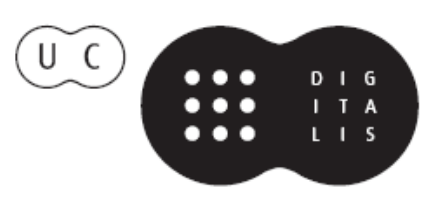


Nair de Nazaré Castro Soares

Santiago López Moreda

Coordenação

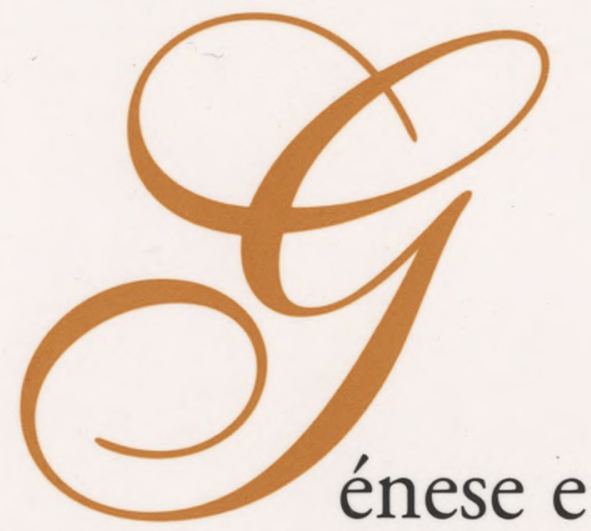

Consolidação da Ideia de Europa

Vol. IV

Idade Média e Renascimento

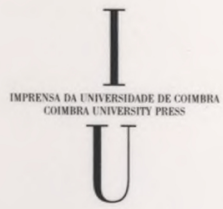

- COIMBra 2009 


\title{
HISPANI OMNES SUMUS? OS NACIONALISMOS DE ANDRÉ DE RESENDE E BARTOLOMEU DE ALBORNOZ
}

\author{
VIRGÍNIA SOARES PEREIRA \\ Universidade do Minho
}

INTRODUÇÃO

A literatura peninsular do século XVI, seja a escrita em vernáculo, seja em latim, deixa muitas vezes entender que as relações entre Portugueses e Castelhanos não eram muito amistosas, apesar do intenso intercâmbio cultural existente entre ambos os povos e das estreitas ligações e contratos acordados entre as duas casas reinantes. Do lado português, a situação agudiza-se na segunda metade do século, quando se torna patente o estado periclitante do reino, cuja continuidade dependia da saúde frágil de um jovem rei, que tinha a paixão da caça e sonhava glórias africanas. Receava-se já então o que veio depois a acontecer: que a coroa passasse às mãos dos Castelhanos - a "desaventura de Portugal", no dizer de Pero Roiz.'

Não admira, portanto, que se desenterrassem então, de parte a parte, antigas questões históricas e se reacendessem velhas polémicas, que tradições bem arreigadas não ajudavam a deslindar.

Assim aconteceu com André de Resende, um dos humanistas de maior renome do século XVI português. Desde sempre revelara gostos de antiquário e interesse pela história pátria e peninsular, mas na parte final da sua vida passou a orientá-los num sentido determinado, apostado em extrair desses estudos os méritos e as excelências de Portugal - ou antes, da Lusitânia, como gostava de dizer - face à vizinha Castela. Com esse objectivo procurava argumentos nas mais diversas fontes, arqueológicas, históricas, epigráficas, geográficas,

${ }^{1}$ Pero Rolz, Memorial, in J. Verissimo Serrão, A Historiografia Portuguesa, I, Lisboa, Verbo (1972: 365). 
hagiográficas e mesmo lendárias, tentando dessa forma responder firmemente às pretensões do país vizinho, que via como um rival. Foi o que fez, concretamente, na epístola que em 1567 escreveu, de Évora, a Bartolomeu de Quevedo, sacerdote da igreja de Toledo. ${ }^{2}$ Nessa carta, a que deu publicidade nesse mesmo $a^{3} o^{3}$ - considerando que abordava questões que reputava de interesse para o reino, conforme diz na epístola dedicatória a D. Sebastião --, o Eborense respondia a dúvidas formuladas por Quevedo, que tencionava escrever uma obra sobre os santos da Hispânia e pretendia conhecer a opinião de Resende sobre alguns pontos controversos de história religiosa. Não se conhece a carta de Quevedo, que se perdeu na voragem do tempo, mas é de supor, pela resposta apaixonada de Resende, que o cónego de Toledo seguia a tese dos seus compatriotas e sonegava alguns santos ao património português. Daí que o Eborense, na resposta, aproveite o ensejo para desferir um violento ataque contra os Castelhanos, acusando-os de desenfreada megalomania, de orgulhoso desdém e, paradoxalmente, de uma encoberta apetência por um cantinho da Europa tão pequeno como Portugal.

Bartolomeu de Quevedo morreu dois anos depois (em 1569) sem ter respondido à carta e ao libelo acusatório de Resende. Sabe-se, no entanto, que lhe teria desagradado o seu tom polémico e o facto de as palavras da sua carta terem sido deliberadamente distorcidas pelo Eborense. Esta informação é-nos facultada por um outro espanhol (mais propriamente, castelhano), Bartolomeu de Albornoz, numa carta que dirigiu a Resende e na qual pretendeu, segundo diz, desagravar a afronta feita pelo humanista português à nação castelhana, aos seus santos e ao próprio Quevedo. ${ }^{4}$ Como se verá, às queixas e ironia de

${ }^{2}$ Vide ANDRÉ DE RESENDE, Carta a Bartolomeu de Quevedo. Introdução, texto latino, versão e notas de Virgínia Soares Pereira, Coimbra, Centro de Estudos Clássicos e Humanísticos da Universidade de Coimbra, 1988.

${ }^{3}$ Em carta de que falaremos a seguir, o castelhano Bartolomeu de Albornoz censura Resende por ter dado "publicidade" (publicando-a) a uma epístola que deveria ser uma resposta privada a outra (a de Quevedo) do mesmo teor. Mas esquecia-se de que a correspondência dos humanistas procurava ser actuante e só publicitada (mesmo que fosse num reduzido círculo de amigos) o conseguiria. Sobre este aspecto vd. HelENE HaRTH, "L'epistolographie humaniste entre professionalisme et souci littéraire: l'exemple de Poggio Bracciolini", in La Correspondence d'Erasme et l'épistolographie humaniste, Bruxelles, 1985 , p. 136 e seguintes.

${ }^{4}$ A carta ficou manuscrita. Vd. B. N. de Madrid, MS. 5556, fol. $7 r$ e $v$ : "estas son las palabras / de V. Md. y como yo san fielmente las pongo gustara mucho que pusiera V. m. las de la carta que le escriuieron porque entre otras cosas que ei seiior licenciado Quevedo antes que muriesse se me quejo por su carta fue que $\mathrm{V}$. m. le retorcia las palabras de la suya y que se las falcaua ( $\mathrm{sic}$ ) dandole por respuesta lo mismo que el decia y otras vezes dissimulando lo que el preguntaua y por no se auer quedado original de la carta que embio no me lo podria 
Resende responde Albornoz com desusada virulência, e toda a espécie de argumentos the serve para atingir o seu fim último: denegrir os Portugueses em geral e Resende em particular.

Esta carta ficou inédita. Encontra-se transcrita em dois manuscritos da Biblioteca Nacional de Madrid. ${ }^{5}$ Por estar incompleta, falta-lhe a datação final, mas da sua análise interna conclui-se que terá sido escrita no ano de 1571 ou pouco depois. ${ }^{6}$ Não se sabe se Resende, que morreu em Dezembro de 1573, chegou a recebê-la, mas o seu tom fortemente desabrido e demolidor pode ter sido a causa do espesso manto de silêncio que a envolveu até hoje.

As duas cartas (a de Resende e a de Albornoz) documentam claramente que o sentimento de animosidade entre Portugueses e Castelhanos estava então ao rubro.

Os tempos hoje são outros e as polémicas também. Por isso, ao retomar agora um tema que ao longo dos meus estudos resendianos me tem interessado de modo especial, ${ }^{7}$ não pretendo reabilitar velhos fantasmas e ressentimentos, mas sim ver como figuras relevantes de humanistas e homens cultos do século XVI

demostrar /.../". Vd. também fol. 53r: "porque solo este capitulo muestra ser verdad lo que el señor licenciado quebedo me escrivio que V. md. ni entendió su carta ni della alega cosa con verdad." Na transcrição de passos desta carta, respeitou-se a grafia, que não é homogénea, mas separaram-se ou aglutinaram-se palavras segundo o critério moderno, para facilitar a leitura e por não revelarem comportamento homogéneo; além disso, desfizeram-se as abreviaturas, deixando apenas V.md. e variantes desta, por constituírem uma fórmula de tratamento.

5 A carta figura nos MSS. 5556 (ff. 1r - 54v) e 6947 (ff. $284 \mathrm{r}-334 \mathrm{r}$ ) da Biblioteca Nacional de Madrid, e ostenta o seguinte título: Carta del Doctor Frias de Albornoz, natural de Talavera contra el Mro Andrés Resende, Portugués, natural de Ebora, y contra la carta que el dicho Maestro Resende imprimió, y embió al Licenciado Bartholomé de Quevedo, Racionero de Toledo. As citações feitas neste artigo são extraídas do MS. 5556, ff. 1r - 54v. Das pesquisas efectuadas, foi possível saber que a carta constava do Catálogo da Biblioteca do Padre Jesuita Marcos Burriel (Cuenca, 1719-1762), um sacerdote cuja actividade incansável de recolha e pesquisa de documentação existente nos arquivos de Toledo e de outras localidades de Espanha, de que foi encarregado por comissão régia, elevou a historiografia espanhola a altos níveis, como pode ler-se no "Repertorio bibliográfico de la Biblioteca del padre Burriel", de Juan Carlos Galende Díaz, in Espacio, Tiempo y Forma, série IV. Historia Moderna, t. 8, 1994, 241-268 (referência à carta na p. 263).

${ }^{6}$ Sobre alguns indícios datadores da carta, veja-se V. S. PEREIRA, "André de Resende e os Portugueses segundo Bartolomeu de Albornoz", in Humanismo Português na época dos Descobrimentos, Coimbra, Faculdade de Letras (1993) 91-107, pp. 93-94 (n. 5).

${ }^{7}$ Tratei o tema sobretudo nos artigos: "Os Castelhanos segundo André de Resende", Diacrítica 1 (1986) 147-166 e "André de Resende e os Portugueses segundo Bartolomeu de Albornoz", art. cit. (vd. n. anterior), e ainda em ANDRÉ DE RESENDE, Aegidius Scallabitanus. Um diálogo sobre Fr. Gil de Santarém. Estudo introdutório, edição crítica, tradução e notas de Virgínia Soares Pereira, Lisboa, Fundação Calouste Gulbenkian, Fundação para a Ciência e a Tecnologia, 2000. 
olhavam para si mesmos e para o seu país com os olhos do astigmatismo nacional... ${ }^{8}$ Perceber-se-á então quanto caminho se percorreu até hoje e como, no processo de construção da Europa moderna, sempre os povos persistiram em entender-se, mas preservando sempre a sua diversidade.

\section{O CASVS BELLI}

Como se disse, foi André de Resende quem, tornando pública a sua Carta a Bartolomeu de Quevedo, provocou a ira de Albornoz. Trata-se de uma extensa missiva (cinquenta e nove páginas), redigida em latim, na qual o Eborense desenvolvidamente discute, entre muitas outras questões de menor peso, os seguintes assuntos:

- o paradeiro das reliquias de S. Vicente de Saragoça: segundo a versão tradicional portuguesa, de que Resende comunga, as reliquias estão em Lisboa; segundo os Castelhanos, que apoiam a versão francesa, elas estão numa povoação da Aquitânia (quinze páginas) ${ }^{9}$

- a naturalidade dos santos Vicente, Sabina e Cristeta, irmãos martirizados no tempo de Daciano: para os Portugueses, esses santos são eborenses, da Évora portuguesa; para os Espanhóis, são naturais de Talavera, que outrora se teria chamado Elbora, à semelhança do que aconteceu com Évora; ${ }^{10}$

- a existência de um Santo Eugénio, no séc. I d. C., que teria sido o primeiro bispo de Toledo (opinião dos Espanhóis, de que Resende discorda) e, associado a este problema, um outro: o de saber se a dignidade de Primaz das Espanhas pertenceu primeiro a Braga ou a Toledo (cerca de seis páginas). ${ }^{11}$

${ }^{8}$ Sobre o nacionalismo português e as suas raízes, bem como sobre a necessidade de Portugal manter a sua identidade própria, vejam-se os artigos bem documentados de R. M. ROSADO FERNANDES, que têm o interesse de procurarem entender os fenómenos de hoje à luz do passado (ou vice-versa): "Raízes do nacionalismo português" e "André de Resende e o Humanismo europeu", in Em busca das raizes do Ocidente, I, Lisboa, Alcalá, 2006, pp. 295-315 e 349-371.

${ }^{9}$ A história de S. Vicente e a chegada do seu corpo a Lisboa tinham já sido tratadas por Resende no poema épico Vicentius Leuita et Martyr, saído a lume em Lisboa, na tipografia de Luís Rodrigues, no ano de 1545.

${ }^{10}$ A encerrar este tema, que lhe ocupou vinte e três páginas, Resende escreve: "Bom! Sobre este assunto disse mais do que pensava. Mas foi, por assim dizer, necessário, para provar que foi deste germe que brotou a alteração do nome de Talavera em Élvora. E que indivíduos como eles não toleram a ideia de que os três mártires tiveram por mãe a nossa terra, por ama a nossa gente" (Carta a Quevedo, op. cit., p. 131).

${ }^{11} \mathrm{O}$ verdadeiro titulo da carta, Pro sanctis Christi martyribus Vincentio, patrono Olisiponensi, Vincentio, Sabina et Christhetide, Eborensibus ciuibus, et ad quaedam alia responsio aponta já para os dois principais temas e para o tom empenhado do seu trata- 
Todas estas questões se prendiam com o património religioso português e Resende não estava, naturalmente, disposto a abdicar das pretensões nacionais. Por isso, afia a pena e desmonta um a um os argumentos da parte contrária, para provar que as posições portuguesas são justificadas e que, ao negarem tais pretensões, os Castelhanos mais não fazem do que dar 'asas' ao seu ego megalómano, apoderando-se ilegitimamente do que lhes não pertence. E dá exemplos concretos dessa visceral mania castelhana, como sejam: consideram S. Dâmaso e Viriato espanhóis, quando se sabe que são portugueses; nunca esclarecem a nacionalidade do rei Vamba, porque foi português; quase ignoram a participação portuguesa na batalha do Salado; desvalorizam a intervenção dos Portugueses na expedição a Tunes, organizada por Carlos V; evitam dizer que Santo António foi português; apagam nas suas obras referências elogiosas ao trabalho dos Portugueses. Em suma: segundo Resende, os Espanhóis diminuíam sistematicamente o valor dos Portugueses para aumentarem o seu. Mas os Espanhóis também tinham as suas queixas, de que Quevedo se faz eco. Consideravam eles que, ao utilizarem a designação de Lusitânia para o seu reino, os Portugueses se engrandeciam, já que uma boa parte da antiga Lusitânia integrava agora o reino espanhol. ${ }^{12}$ Resende responde: o título de "reino da Lusitânia" é tão legítimo como o título de "reino da(s) Hispânia(s)" que se arrogam os Espanhóis.

E no entanto, concluía, Hispani omnes sumus, "todos nós somos Hispanos"... Era a pura verdade - Hispanos eram todos quantos habitavam a Península -, mas as suas palavras, que se revelaram de uma ironia amarga, disseram talvez mais do que o próprio Resende teria querido dizer, ele que tanto se empenhara em provar a antiguidade e a independência da Lusitania face ao resto da Península. ${ }^{13}$

mento. Para um conhecimento mais pormenorizado da carta, vd. a referida Carta a Bartolomeu de Quevedo.

${ }^{12}$ NEBRIJA, por exemplo, num dos "prolegomena" à obra sobre os feitos de Fernando e Isabel (vd. Hispania Illustrata, I, 1603, p. 793), refere com desagrado esta apropriação, mas não deixa de usar, por comodidade ou hábito, os termos criticados (Lusitania e Lusitani). Um outro autor não concorda com a designação porque, segundo diz, à Espanha apenas faltam dois deditos (a saber: Portugal e Navarra) para ser Hispânia (vd. A. C. RAMALHO, Estudos camonianos, 1980: 10). Reflexo sintomático da posição castelhana, entre nós, surge no prólogo da Comédia Eufrosina, de J. F. de Vasconcelos, onde João d' Espera Deos, referindo-se aos Lusytanos, acrescenta: "que a pesar de invejosos sam Portugueses".

${ }^{13}$ Vd. Carta a Quevedo, op. cit., pp. 130-139 (texto e tradução) e 43-48 (comentário). No contexto da Península Hispânica, Portugal, país de finis terrae, encravado entre o vasto oceano e a meseta castelhana, evitava a diluição no conjunto manifestando-se diferente: Lusitano. Se recordarmos que a carta de que temos vindo a falar foi escrita em 1567, isto é, num periodo em que o futuro D. Sebastião ainda não governava, em que o Cardeal Infante 
Perante tais argumentos, Albornoz reagiu e contra-atacou, na extensa carta (54 fólios mss., apesar de incompleta) que dirigiu a Resende. Aí, devolve uma a uma as afirmações e as insinuações de Resende, invalidando os seus argumentos, que considera falaciosos, e pondo em relevo os erros que, em seu entender, recheiam o texto do Eborense. Albornoz era jurista: estava pois preparado para esgrimir argumentos, assinalar contradições, detectar falácias. Mas fez mais: semeou a carta de injúrias e vitupérios lançados contra Resende e os Portugueses. Expliquemo-nos: na sua carta, Resende referira-se a Lucas de Tui, Florião Docampo e outros cronistas espanhóis usando epítetos depreciativos como nebulones, patetas e ignorantes. Albornoz pensa então no epíteto que melhor quadraria a Resende, e passa a tratá-lo por "Señor portugués", dando desta forma o tom a uma carta na qual os Portugueses são qualificados de bárbaros, ignorantes, orgulhosos e judeus, sendo Resende, por seu turno, erigido a protótipo do produto nacional e considerado um ídolo amplamente incensado mas com pés de barro...

Quem era este Bartolomeu de Albornoz que tão acintosamente afrontava André de Resende? Os dados de que dispomos são escassos. Segundo Nicolau Antonio, nasceu em Talavera, foi professor de Direito na recém-fundada Universidade do México (1551) e era dotado de um talento e memória inexcedíveis. Em 1573 foi publicada em Valência a sua Arte de los Contratos, dedicada a D. Diego de Covarrubias, que fora seu mestre. Apesar de se tratar de uma obra de natureza jurídica, chegou a ser proibida pela Inquisição, devido $\grave{a}$ incontinência sarcástica de alguns dos seus passos. ${ }^{14}$ Entre as obras manuscritas que deixou, referidas por Nicolau Antonio, não figura a carta a Resende, de que aqui tratamos. Mas esta fornece-nos outros dados, como sejam: estudou em Alcalá, onde foi discípulo de Gaspar de Castro; foi neto de Gil Gomez de Albornoz e sobrinho de Aurelio de Albornoz, e pensava escrever uma Cosmografia de Espanha. ${ }^{15}$

D. Henrique conduzia os destinos do reino de forma pouco hábil, incapaz de impedir a interferência constante da corte espanhola (através de D. Catarina, viúva de D. João III e avó de D. Sebastião) na vida portuguesa, se recordarmos estes e outros factos de uma história nebulosa em que o futuro se vai fazendo a favor dos Espanhóis, então compreenderemos as apreensões (ainda que não explícitas) de André de Resende.

${ }^{14}$ Vd. Nicolau AntoniO, Bibiiotheca Hispana Noua, t. 1, Madrid, 1783, p. 194.

${ }^{15}$ São os seguintes os passos que fornecem estes dados: "como lo mismo acaecio en Alcala de henares que siendo yo enella estudiante era tenido por pestilente y inabitable los veranos" (fol. 21r, sobre o clima doentio de Alcalá no verão); sobre Gaspar de Castro, de quem fala com admiração, diz: "mi maestro que aya gloria hombre doctissimo excellente antiguario" (foi. 40v); sobre o tio e o avô: "el doctor Aurelio de Albornoz mi tio y maestro" (foi. 9v); "asi la llaman los dos hermanos Albornoces mi padre y tio y entrambos mis maestros de los mas doctos hombres deuropa" (foi. $12 \mathrm{v}$; sobre o nome Elbora, dado a Talavera 
Encontrou-se uma ou mais vezes com Resende, e este admirava-o, como pode ver-se por uma epístola não datada, mas provavelmente de 1566 , que escreveu a Albornoz. ${ }^{16}$ Talvez por isso, e para justificar o tom indelicado da sua carta, Albornoz comece por estabelecer uma distinção, baseada em exemplos clássicos, entre amizade e dever patriótico. Nas palavras expressivas de Albornoz, a carta tinha dois objectivos bem explícitos: "pagar a mi patria du deudo y a V.M. su merecido" (fol. $2 \mathrm{v}$ ), isto é, vingar a sua terra injuriada e castigar a ousadia de Resende. Para o fazer, esclarece, recorrerá à sua tríplice qualidade de cidadão natural de Talavera, castelhano e cristão. E assim acontece. Como natural de Talavera, defende a posição daqueles que vêem em Elbora um nome antigo de Talavera, e afirma a naturalidade castelhana dos santos Vicente, Sabina e Cristeta, que Resende e os Portugueses indevidamente reclamam como seus. Insere, além disso, em jeito de excurso, uma longa descrição (e elogio) de Talavera (ff. $21 \mathrm{v}-32 \mathrm{v}$ ). Na qualidade de Castelhano, devolve a

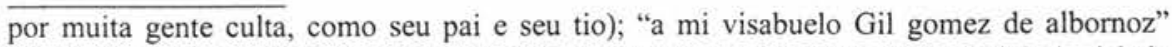
(fol.20r); relativamente à Cosmografia que tencionava escrever: "Talavera la vieja /.../ de la qual em mi cosmographia de España tratare mas largo" (fol. 10v.).

${ }^{16}$ A carta que Resende escreveu a Albornoz, bastante elogiosa, chegou até nós porque foi incluída por Diogo MENDES DE VASCONCELOS na sua edição do De Antiquitatibus Lusitaniae, publicada em Évora em 1593, donde transitou para edições posteriores da mesma obra, Como the falta a datação final, não se sabe quando foi escrita. CAROLINA MiCHAELLIS datou-a de 1565, baseada no facto de nela Resende atribuir a Públia Hortência de Castro a idade de dezassete anos (vd. A Infanta D. Maria de Portugal e as suas damas, Lisboa, Biblioteca Nacional, 1983, pp. 111-113 e nota 18). Nessa carta Resende lamenta o zelo excessivo e a tacanhez de espírito do então vice-governador da cidade de Évora, que impediu a entrada de Albornoz na cidade por se suspeitar que vinha de Sevilha, onde então grassava a peste. E recorda vagamente o dia que passaram juntos na sua casa de campo, em agradável, mas a bem dizer secreta, cavaqueira. Das suas palavras é possivel, talvez, concluir que esse encontro se deu antes de Albornoz pretender entrar na cidade. Seja como for, é provavelmente a esta vinda de má memória a Portugal que Albornoz alude quando, na carta de que tratamos, escreve: "quando fuy que no debiera a Portugal" (fol.11r). E, se não se encontraram nesta altura (c. 1565), reuniram-se noutra ocasião, como se comprova com outros passos da referida carta. Diz Albornoz: "Aclarandome mas, digo que lo que V.md. pretende en este passo es dar a entender lo mismo que commigo trato de palabra. que nunca en españa ubo silla que tubiese Primacia sobre todas las demas" (fol. 47v). Num outro passo: "esto es enquanto a los Auctores Antiguos que como otra vez he dicho a V.md. le son communes conmigo y no son mas propios mios que de todos los estudiosos" (fol. 34r). Um ou mais encontros teriam suscitado uma admiração mútua, portanto. Só assim se compreende a razão pela qual Albornoz, logo no inicio da carta, justificou o tom agressivo dela e fez protestos de amizade: "a todos y a V.M. primero pido perdon de la ofensa si alguna por esta scriptura rescibiere, pues la deuda que a mi Rey patria e nacion todos deuemos naturalmente y yo deuo me hizo tomar la pluma, y fuera desto la obligacion particular que e dicho [sc. a amizade] queda en mi tanto i mas fuerte que nunca estuvo para todo lo que de mi se quisiere servir" (fol. 2r). 
Resende a acusação de megalomania e brinda os Portugueses com epítetos pouco abonatórios. Como cristão, diz mal dos criptojudeus e distancia-se dos "gramáticos" de pouca fé.

$\mathrm{Na}$ longa carta de Albornoz sucedem-se os argumentos e os contra-argumentos, aos excursos somam-se outros excursos, às citações outras citações. Todavia o argumento mais demolidor acaba por ser a sua persistente veia sarcástica, que combate especialmente em duas frentes: contra Resende e os "gramáticos"; contra Resende e os Portugueses. É nesta dupla faceta que a carta será agora analisada.

\section{ALBORNOZ CONTRA RESENDE E OS GRAMÁTICOS}

O termo "gramático" (grammaticus), que designava então os humanistas, tem em Albornoz um sentido profundamente pejorativo. ${ }^{17}$ Considerava os gramáticos de profissão gente da pior espécie: ignorantes e sobranceiros, diziam mal de tudo e de todos, eram grandes "correctores" de livros porque os não entendiam, atreviam-se a invadir todas as áreas do saber só porque sabiam latim, eram a própria encarnação da arrogância. Além disso, sugeria, eram gente pouco apegada à fé cristã.

Estes ataques faziam parte de um longo rol de acusações geralmente endereçadas aos gramáticos por aqueles que não gostavam de ver o seu saber sujeito à lupa crítica (por vezes hipercrítica e deformadora) do labor filológico. Neste ponto, Albornoz não estava isolado e seguia a corrente do seu tempo. Era jurista, e a polémica entre gramáticos e juristas, que tivera em Valla o seu detonador (ao criticar o latim e a ciência de Bártolo), irrompeu um pouco por toda a parte, no século XVI. Os humanistas consideravam a grammatica a pedra angular e o fundamento de qualquer ciência, a ianua scientiarum, como gostavam de chamar-lhe; os juristas, por sua vez, entendiam que eram mais úteis à estabilidade e progresso dos povos e a prova disso é que a sociedade lhes pagava bem melhor... ${ }^{18}$ Apesar disso, Nebrija, o debelador da barbárie,

\footnotetext{
${ }^{17}$ Note-se que Albornoz não desconhece o termo humanista, mas reserva-o para figuras por quem tem particular apreço, acompanhado por vezes, do epiteto "docto'. Veja-se, por exemplo, o passo em que refere vários homens de letras que deram a Talavera o nome de Elbora: "asi la llamo el maestro herrera y su hijo que fueron en España los mayores umanistas della, asi la Ilaman los dos hermanos Albornoces mi padre y mi tio y entrambos mis maestros delos mas doctos hombres deuropa, asi la llamo Gutierre Gomez de Toledo, natural della y grande umanista en los versos que hizo de su studio, y la llama Juan de Malara docto umanista de Seuilla /.. ./(fol. 12v).

${ }^{18}$ Exemplo clássico, entre nós, desta luta entre juristas e humanistas é Inácio de Morais, que de professor de Poesia se transferiu para o campo do Direito e (ardor da neófito?) escreveu um In quosdam Dialecticos \& Grammaticos, pro Iure peritis, um manifesto
} 
tinha, como Aires Barbosa e outros, orgulho na sua profissão de grammaticus, e considerava o gramático como o médico da ignorância, ao qual todos os doentes, fossem teólogos, juristas, príncipes ou reis, deviam obedecer. Tal soberba científica desagradou a muitos e era frequente ouvir, aplicada ao mestre de gramática, as palavras que Apeles dirigiu ao sapateiro: não fosse além da chinela...

Desconhece-se se Resende, que prezava a sua profissão e por mais de uma vez lamentou o desapreço com que era encarada, recebeu a carta (escrita talvez em 1571 ou depois), mas, a tê-la recebido, não há-de ter gostado do que leu, ele que tinha dedicado a sua vida a uma profissão tão injustamente vilipendiada por Albornoz, que para mais altivamente afirmava detestar a gramática e se apresentava como "jurista barbaro".

É o que podemos ver num passo em que, depois de fazer uma longa prelecção gramatical acerca da supressão sistemática, em português, da líquida lateral, e da sua manutenção (e mesmo acrescento) em castelhano, para provar que Elbora era um vocábulo castelhano, escreve:

mas por vida del Sr. Maestro que le paresce deste castellano que sin saber latin $n i$ griego a V.M. que es el gran Idolo de Portugal no le pone incienso ni le sacrifica sino que quiere mostrarse del diestro en su lengua Portuguesa y dar a entender que V.M. ni sabe hablar ni aun entender la lengua en que nacio quanto mas las agenas en que muestra su ynorancia escarneciendo y mofando de los escriptores antiguos maestros de todos a quien deuemos lo que sabemos (fol. 12v).

Como se vê, Resende é, na pena verrinosa do jurista, "el gran Idolo de Portugal", a quem todos prestam culto. Mas tendo os ídolos normalmente pés de barro, não é de estranhar que, noutro passo tão contundente como este, Albornoz contradiga a ciência de Resende no domínio da cosmografia:

/.../ que se mete en lo que ni sabe ni entiende y en lo que a otros reprehende comete herrores intolerables especialmente enesto de la Cosmographia que sin razon V. Md. ha tenido encantada a España, y aun los de fuera della pensando que era el oraculo en lo que meno sabe mas que un buey /.... Mas V.md. deme licencia que lo diga, siendo un simple grammatico ignorante y Portugues, porque lo hade hazer y meter la mano en corregir a otros en la sciencia de que no tiene principios, bien bastaua lo

a favor do Direito e contra os gramáticos, onde só o quosdam suaviza (ou restringe) um pouco o alcance do ataque. Ao contrário de Aires Barbosa, que tentara dignificar o termo Grammaticus, mostrando a sua afinidade etimológica com litteratus, Inácio de Morais aconselha o gramático a circunscrever-se ao seu terreno, a não meter a foice em seara alheia, como diz. Sobre esta querela, veja-se NUNO EsPINOSA GOMES DA SILVA, Humanismo e Direito em Portugal no século XVI, Lisboa, 1964, pp. 202-204 e 258-262. Recorde-se também que André de Resende se queixa, por mais de uma vez, de que na Corte pontificam os juristas, enquanto os professores de letras são marginalizados. 
que le hemos tractado de Elbora de Munda y de Badajoz por que sepa ueia y entienda como ninguna cosa sabe de Cosmographia /.../ (fol. 36r).

Esta invectiva tinha origem no facto de Resende ter censurado Valenzuela, teólogo e pregador andaluz, por se ter referido, num sermão em Coimbra, aos famosos campos de Munda, como se Coimbra e Munda fossem a mesma terra. Para quem pregava a "gente vã e portuguesa" (comentava Albornoz), o erro não era grave. Grave era, em sua opinião, escrever disparates no Breviário, como fizera Resende. $^{19}$

Outra das críticas feitas por Albornoz é a de que Resende, quando não tem argumentos sólidos, se socorre de piadas e formulações sofisticas, coisas que ficam muito mal, mesmo a gramáticos. ${ }^{20}$ Quer dizer: até do ponto de vista ético o título de gramático era desprestigiante.

De resto, Resende não está só. A emparceirar com ele, nesta profissão de má fama, surgem Nebrija e Juan Maldonado. Ambos tinham identificado Elbora com a Évora portuguesa, contra a opinião de outros espanhóis, como Albornoz, que em Elbora querem ver uma antiga designação de Talavera. E o Castelhano comenta:

V.m. y ellos que es un sancto colegio trium viral de grammaticos construyeron mal la letra y corrigieron por herrado lo que no entendian (fol. 13v).

Ao tratar da questão do paradeiro das relíquias de S. Vicente, Resende estabelecera, na Carta a Quevedo, uma comparação entre S. Boaventura e Plátina, concluindo que se devia dar mais crédito a S. Boaventura, cuja seriedade era incomparavelmente superior à do Plátina, e que dizia que essas relíquias estavam em Lisboa. Albornoz não gostou desta confusão de planos: ser santo é uma coisa, ser douto é outra. Se a bitola da comparação fosse a santidade, a vitória pertenceria a S. Boaventura; mas em matéria de conhecimento histórico a palma deverá ir para Plátina - e, consequentemente, o corpo de S. Vicente está numa região da Aquitânia, como afirma este humanista.

${ }^{19}$ Veja-se como compara o erro de Valenzuela (num sermão) e o de Resende (impresso com todas as letras): "Creame que neçedad en sermom que se pasa, mas neçedad de molde es bienes Rayzes, la neçedad en sermom es neçedad de palabra, mas neçedad en lecion de Breuiario es neçedad en canto llano donde son letras pocas y gordas, al fin es neçedad firmada de su nombre de V. Md. A la maldicion neçedad cantada (ff. $35 \mathrm{r}-\mathrm{v}$ ).

${ }^{20}$ Assim, depois de provar a antiguidade de Talavera (contra o parecer de Resende), Albornoz acrescenta: "y desta manera querria que V.M. provasse las cosas que quiere persuadir y no con risas ni sophesterias prosopopeyas que aun entre grammaticos son cosas de verguenza" (fol. $4 \mathrm{v})$. 
Albornoz conseguiu assim defender a sua posição, mas não sem antes ter desferido mais uma das suas farpas contra os gramáticos. Eis a farpa anticiceroniana:

Platina fue de la escuela de Pomponio Leto que tenian para su consolacion unos pocitos de Dioses, celebravan el nacimiento de Romulo y por concluir en una palabra erã de Ia profesion de V.md. grammaticos, y a esta causa Platina se arrebato ciertos tormentos del Papa Eugenio Paulo $2^{\circ}$ por gentil (fol. 46r). ${ }^{21}$

A acusação é agora mais insidiosa, porque sugere que os humanistas paganizavam e prestavam mais culto ao passado greco-romano do que à religião cristã. Noutro passo Albornoz afirmara que, ao escrever esta carta, pretendia penitenciar-se da cegueira em que ele e muitos outros tinham vivido - e nisso Resende não estava isento de responsabilidades - por se preocuparem em saber mais dos deuses pagãos e gentios do que dos seus santos, e, relativamente a estes, por procurarem saber onde nasceram, em vez de quererem saber como viveram e imitá-los. ${ }^{22}$ Esta alfinetada atingia quem quer que, nas histó-

${ }^{21}$ Albornoz refere-se à chamada "Academia" romana dirigida por Pompónio Leto, em cuja casa se reunia um grupo de intelectuais que apaixonadamente se dedicaram ao estudo da antiguidade clássica, mas que, no tempo de Paulo II, foram acusados de heréticos e de crenças e práticas pagãs. Desse grupo fazia parte Plátina, ou seja, Bartolomeo Sacchi de Cremona. Além da acusação de paganismo, uns e outros foram acusados de conjura contra o papa (o referido Paulo II), pelo que foram perseguidos e alguns presos, como Plátina. Perdeu o seu cargo de abreviador pontificio, mas, no tempo de Sisto IV, é chamado a dirigir a bíblioteca Vaticana. A este papa dedica uma das suas obras mais conhecidas, as Vitae Pontificum, que terminam justamente com uma violenta diatribe contra Paulo II. Acrescente-se que ainda hoje se discute da total veracidade das acusações lançadas contra estes humanistas. Sobre este assunto vejam-se, por exemplo: VitTORE BRANCA (Dir.) Dizionario critico della letteratura italiana, Torino, 1974, s.u. Platina; EMILIO CECCHI e NATAlino SAPEGNO (Dir.), Storia della letteratura italiana: il Quattrocento e l'Ariosto, Garzanti Editore s.p.a., 1988 (Ristampa 1990) pp. 144-160 ("L'Academia romana, Pomponio Leto e la congiura").

${ }^{22} \mathrm{O}$ passo merece ser citado. Albornoz começa por confessar que em tempos foi da opinião expressa por Vaseu no seu Chronicon sobre a naturalidade portuguesa dos santos Vicente, Sabina e Cristeta, inspirada em Resende, mas que depois viu o erro em que estava, e acrescenta: hasta que leyda la carta de V.m. entendi su engaño y enel que a todos con su autoridad nos auia puesto, y en penitencia de mi herror acorde de escreuir esta para que se sepa la verdad, lo qual refiero para confusió mia y de todos los que enesta ceguedad biuimos que si me preguntan de qualquiera de los Dioses antiguos de griegos romanos egipcios y otras naciones barbaras parlare mas que un papagayo y declarare su Theologia y rritus como se uviera sido sacristan de cada uno dellos, y en llegando a nuestros Sanctos gloriosos ya estoy mas torpe que si aora fuesse nuevamente convertido a la ley $(20 \mathrm{v}-21 \mathrm{r})$. Também a propósito do frade Valenzuela e da sua confusão de Munda com Coimbra, Albornoz, depois de recordar que outros autores caíram no mesmo erro, acaba por reconhecer que não 
rias da vida dos santos, prestava mais atenção aos aspectos exteriores e históri$\cos$ da vida (local de nascimento, parentesco, estudos) e não à sua exemplaridade, como defendiam os erasmistas, que advogavam a primazia da religião interior. Mas é possível que Albornoz pensasse concretamente em Resende, que, como humanista, em todas as suas obras de teor hagiográfico revelava uma grande tendência para tratar as vidas dos santos sub specie philologiae. Esta inclinação estava então inequivocamente associada a uma questão 'fracturante' (como hoje se diria) - a questão do Ciceronianismo, que para muitos era sinónimo de paganismo. ${ }^{23}$ Albornoz não deixará de lhe fazer referência, ainda que fugaz e sub-repticiamente. ${ }^{24}$

Em sintese: no século XVI, com a difusão do erasmismo, "grammatico" era "um termo carregado de conotações pejorativas e, o que é pior, de perigosas associações". ${ }^{25}$ Com o avançar do século, aumentam de intensidade as críticas à soberba e heterodoxia dos gramáticos. ${ }^{26} \mathrm{~A}$ carta de Albornoz reflecte bem este ambiente.

Ihe agradam frades ignorantes, embora acrescente que, se tivesse de escolher entre a ignorância e a frieza da fé, não teria dúvidas na opção. Censura, por isso, quem está sempre atento a uma falha num sermão, dizendo que El pulpito es cathedra de Jesu Christo donde ade aprender su doctrina y no Grammatica ni Cosmographia. E acrescenta: No digo esto porque me satisfagan los clerigos ó predicadores ignorantes, porque aunque fuesen Tullio y Demosthenes no ternian tanta doctrina como aquellos lugares merezen, mas quiero mostiar mi opinion, quando de las dos cosas ha de faltar la una qual me pareze que haze menos falta (foi. 34r).

${ }^{23}$ Sobre este aspecto da obra resendiana, veja-se André de Résende, Aegidius Scallabitanus. Um diálogo sobre Fr. Gil de Santarém. Estudo introdutório, edição crítica, tradução e notas de Virgínia Soares Pereira, Lisboa, Fundação Calouste Gulbenkian, Fundação para a Ciência e a Tecnologia, 2000, pp. 173-182.

${ }^{24}$ A farpa critica de Albornoz está relacionada com a contenda entre Ciceronianos e anti-Ciceronianos, isto é, entre os fiéis discípulos dos hábitos linguísticos e retóricos do maior orador romano e os que consideravam impossível traduzir as vivências do século XVI com as roupagens do século I a.C., ciceronianas que fossem. Albornoz não entra declaradamente nesta questão, mas refere-sc ironicamente a uma das facetas do Ciceronianismo: a da preocupação das cláusulas. Assim, depois de criticar o nome de uma familia portuguesa, a dos Cogominhos - um nome que, dizia, the faz lembrar bruxas e cominhos -, aconselha Resende a, com todo o poder de que desfruta, alterar o desagradável nome Cogominhos para outro, e acrescenta: $y$ pues esta en su mano escoger o fingir el que quisierc, sea algun nombre abultado de veynte y cinco o trcynta silabas y vocales abultadas como clausula de ciceroniano que sea menester beuer dos o tres vezes para acabarle de pronunciar (fol. 19r),

${ }^{25}$ Luis Gll., "Grammaticos, humanistas, domines", in Estudios de Humanismo y tradición clásica, Madrid, Editorial de la Universidad Complutense, 1984, p. 58.

26 "Soberba y heterodoxia" é o titulo de um dos capitulos da obra de LUIS GIL, Panorama social del Humanismo Español (1500-1600), Madrid, Alhambra, s.d. [1981]. 
Vimos já como Albornoz se dirige por vezes a Resende epitetando-o de "Señor Portugués", atribuindo a tal epíteto o sinónimo de ignorante e orgulhoso. O mesmo acontece nos passos seguintes:

enestas palabras (nas quais Resende comenta um passo do Itinerário de Antonino) muestra bien V.m. como a leido a Antonino con los mismos ojos que a Plinio y Ptolomeo y que em todos três tiene yguales letras y deven ser las que en ese reyno se usan porque el Pe. Barreyro en el itinerario que hizo tropezo en lo mismo (fol. 10r-v).

Ou então:

la formacion o derivacion de Libora a Elbora es tan clara que ninguno que tenga juycio y aunque no lo tenga aunque fuise un portugues lo puede negar (fol. 12v).

Portugal, como país, não tem melhor imagem junto de Albornoz. Em particular quando comparado com Espanha.

$\mathrm{O}$ caso é nítido na questão da primazia das Espanhas, que em sua opinião coube a Toledo e não a Braga. A respeito de Toledo e da Espanha afirma o seguinte: Toledo era de las mas insignes ciudades de España que es la mas insigne provincia del mundo (fol. 45v). Sublinhe-se esta hipervalorização da Espanha, elogiada como a região mais importante do planeta, e observe-se o raciocínio desenvolvido por Albornoz: Toledo, a mais importante cidade do principal reino de Espanha, o reino de Toledo, fica no centro da principal região do mundo, Espanha. ${ }^{27}$ Que se passa com Braga, que concorria com Toledo na questão da primazia?

${ }^{27}$ No fol. 50r Albornoz escreve: Toledo es la mas principal ciudad del principal Reyno de España que es el de Toledo. Encontramos um outro exemplo desta visão megalómana de Toledo como centro da Espanha e do mundo em Luis Hurtado de Toledo, que compôs em 1576 um extenso Memorial de algunas cosas notables ... de Toledo, em resposta a um questionário nacional, promovido por Filipe II para se elaborarem as Relaciones topográficas de los pueblos de España (vd. F. González Ollé, "Un informe de 1576 sobre eI habla de Toledo y su aplicación como modelo idiomático", in Homenaje a Eugenio Asensio, Madrid, Editorial Gredos, 1988, p. 215). O começo do citado Memorial é de si significativo: El paso de Toledo es para todas las partes del mundo porque en él se hallarád todas las naciones, de todas provincias, de todas artes, de todos oficios, de todos estados e de todas lenguas. Está, como dicho es, en el centro y coraçón de España, y, por el mismo caso, del Mundo (ibid., pp. 215-216). 
I.... por el contrario la ciudad de Braga esta en lo postrero de España y del mundo, y con ser Portugal la mas ruin tierra de España y mas esteril mas despoblada y donde menos contratacion ay de negocios, es la mas ruin tierra de España mas esteril y de menos poblacion y menos contratada de toda la gente del mundo (50r).

Braga, assim expulsa do comércio das gentes, tem ainda um outro senão: o seu nome. Plínio, ao falar do convento jurídico de Braga, evitara registar os nomes dos povos que o habitam por soarem mal. E teve razão, continua Albornoz, porque não era possível dizer o nome de Braga sem sentir nojo ('asco' é o termo que utiliza), por ser, enfim, coisa de bragas... e pelo nome se tirar a coisa, a acreditar no Crátilo de Platão... Paronímia ou falsa etimologia, de tudo se serve Albornoz para denegrir a cidade concorrente de Toledo. Tinha assim razão Resende quando na carta a Quevedo, falando da megalomania castelhana, escrevia, em tom de desabafo e de queixume:

\section{Tam nihili apud uos sumus!}

\section{Tão pequeno é o conceito em que nos tendes! $!^{28}$}

O contraste estabelecido por Albornoz entre Toledo e Braga desemboca num ataque à mania das grandezas dos Portugueses. A bem dizer, a acusação não era falsa de todo, porque, conforme afirmam os estudiosos que trataram do assunto, os Portugueses também tiveram a sua megalomania, que deixaram reflectida em vários textos, em especial nas palavras do vilão de Gil Vicente, que ousou, perante a corte espanhola, proclamar que 'Deus é Português". ${ }^{29}$ Albornoz observou esta faceta

${ }^{28}$ Veja-se o passo: Tam nihili apud uos sumus! Sed estote beati, estote felices, muneribus a Deo concessis gaudete atque dominamini! Sinite nos pauxillo nostro etiam frui! Hispani omnes sumus, magnis inuicem propinquitatibus adfinitatibusque cognati ac familiarum mutua utrimque permixtione consanguinei! "Tão pequeno é o conceito em que nos tendes! Mas, pela vossa parte, sede afortunados, sede felizes, regozijai-vos com os dons que Deus vos concedeu e dominai em toda a linha! Deixai que gozemos também, pela nossa parte, do pouco que nos pertence! Somos todos hispanos, ligados mutuamente por grandes laços de vizinhança e de alianças, somos do mesmo sangue, em virtude de um duplo e recíproco cruzamento de famílias!" (op. cit., pp. 130-131).

${ }_{29}$ Um outro sinal da nossa megalomania pode ver-se, por exemplo, na seguinte afirmação de Fernando Oliveira, no capítulo 2 da sua Granática: "A antiga nobreza e saber da nossa gente e terra de Espanha, cuja sempre milhor parte foi Portugal" (cit. de MARTIM DE AlBUQUeRQue, A consciência nacional portuguesa (Ensaio de História das Ideias politicas), I, Lisboa, s. d., 1974, p. 223, n. 1). É também conhecida uma anedota atribuida a Resende que tem o seu quê de megalómano: "Dizendo um Castelhano a Mestre Andre de Rezende que os Portugueses não eram mais de seis, dos quais/dous/ andavam em demandas, e dous estavam presos nas cadeas, e dous queriam conquistar o mundo, dicelhe Mestre Andre; Pois que fizeron se todos seis quiseram conquistar o mundo." (cit. de A. COSTA 
e considerou que, na sua ousadia de quererem comparar-se com os maiores, os portugueses se comportavam como Lúcifer, que quis ser semelhante ao Altíssimo. Nesta comparação é fácil entender quem tem a condição de Lúcifer decaído...

De seguida, Albornoz passa a acusar os Portugueses de uma mania muito portuguesa (que, como se sabe, foi censurada pelos próprios): a da imitação dos Castelhanos. Apesar da sua dimensão diminuta, queriam sempre ser superiores em tudo. E qual era o resultado?

Todas las cosas dese reyno se enderezan a ser monas de las de Castilla, aca tenemos condestable alla luego le hicieron, en Castilla no ay mas de quatro sillas Arzobispales ya alla an hecho tres que son Braga Lisboa y Ebora y dõde una sola no tenia bastante senorio an hecho aora tres, ya tienem alla mas duques que aca tenemos condes. Mas sabe que diferencia va? la que de la sierpe que hizo Aaron de su vara a las de los magos de Faraon, que la sierpe de Aron era grande y verdadera y si comio a las otras que eran lombrizes fantasticas. (51r)

Eis aqui, nas roupagens de um símile extraído da Bíblia, a ameaça velada e sempre temida: a de que a serpente castelhana viesse a devorar os Portugueses, frágeis e irreais. Estamos no domínio do retórico, onde todos os símiles e ousadias são possíveis, mas Albornoz parecia tomar à letra as suas palavras, ao comentar, em jeito de cínico conforto:

entienda Seõr maestro que no es menor grandeza saber serbir al mayor que mandar alos menores, la ygualdade entre los desyguales es imperfecion natural y la mayoria introdujo la naturaleza y obedeciendo merecio S. Miguel por sugecion lo que Lucifer perdio por soberbia (51v).

Era o mesmo que dizer: tanto o direito natural como o direito divino legitimam o domínio de uns e a sujeição de outros. Também aqui Albornoz vinha dar razão a Resende quando este se queixava do desdém com que os Castelhanos olhavam Portugal e via nele sinais de cobiça. A ameaça aí estava, uma vez mais sob a candura da roupagem bíblica.

Para completar o retrato negativo dos Portugueses faltava ainda brandir o espantalho do judaísmo, e Albornoz não se esquece de o fazer. A acusação, de resto, não era inédita, já que, como observa Nuno Espinosa da Silva, "na mentalidade europeia todo o português era hebreu". ${ }^{30}$

Ramalho, "Ditos e sentenças de quinhentistas portugueses", Humanitas, 29-30 (1977-78), p. 7). Sobre esta questão do orgulho português, vd. Luis DE MATOS, "L'expansion portugaise dans la littérature latine de la Renaissance", in L'Humanisme Portugais et l'Europe. Paris, Fondation Calouste Gulbenkian, Centre Culturel Portugais, 1984, pp. 397-417.

${ }^{30}$ N. EsPINOSA DA SILVA, Humanismo e Direito em Portugal no século XVI, Lisboa, 1964 , p. 291. 
Portugal, segundo Albornoz, estava cheio de judeus, e só a vinda providencial de dois espanhóis, o Saavedra, cordovês e Núncio Apostólico em Portugal, e o tristemente famoso Paredes, tinha posto cobro à situação. Saavedra les metio la Inquisicion en esse reyno que ha quemado la mitad del (fol. 53v); Paredes, cónego e inquisidor de Évora, a essa inquisicion fue llevado de Llerena donde estava en Castella para hazer carbon en Portugal. ${ }^{31}$

$\mathrm{Na}$ óptica de Albornoz, cristão velho, a peçonha não desaparecera de todo, tendo alguns fugido, a contaminar outras terras com as suas práticas judaicas, como Amato Lusitano, os Brudos (discípulos de Resende...) e outros. ${ }^{32}$ Ruim terra que tais frutos dá, comentava, acrescentando que nada disto se aplicava a Resende, a quien Dios hizo mui christiano viejo y hidalgo y limpio (53v). Mas seria bom que, em vez de dizer mal dos outros povos (leia-se: Castela), o português olhasse para o que se passa na sua própria terra que, verdadeiro ninho de judeus, bem merecia as pestes que a assolavam, sinal da ira de Deus e de outras desgraças por vir (54v).

Perante afirmações deste teor, Resende poderia sentir-se tentado a perguntar a Albornoz de onde tinham vindo os judeus a Portugal, mas o remetente

${ }^{31}$ Nas pesquisas efectuadas não foi possível encontrar qualquer referência a este Saavedra. Quanto a Paredes, trata-se do famoso licenciado Pedro Álvares de Paredes, de má memória pela sua actuação na inquisição do Évora. Os ecos da sua crueldade na perseguição aos judeus chegaram a Ragusa e Diogo Pires refere-se-lhe num dos seus poemas, o "De exilio suo" (vd. Carlos A. André, Diogo Pires: Antologia Poética, Coimbra, 1983, p. 125, n. 42). AleXANDRE HERCULANO descreve o zelo inquisitorial deste homem que inventava mil e uma formas de arrancar ao condenado a confissão do crime de judaísmo (vd. História da origem e estabelecimento da Inquisição em Portugal, Lisboa, 1976, III, pp. 143-145). Veja-se ainda, sobre este Paredes, António Borges CoElHo, Inquisição de Évora (Dos primórdios a 1668), vol. I, Lisboa, Caminho S.A., 1987, p. 56.

${ }^{32}$ Eis as palavras de Albornoz: Mas que diremos de Amato Lusitano que se llama Rodrigo de Castelbranco y de los dos Bruduos discipulos de V.Md. y hijos de maestro Donys (sic) Physico mayor del Rey don juan, que no contentos con auerse ydo a ser judios a Salonique escriven desde alla obras para que sepamos como son judios, esto mismo hizo mas Phelippe el Zurujano que hallo la cura de las carnosidades de la orina del qual escrive Laguna que se fue a morir a Jerusalem (ff. $54 \mathrm{r}-\mathrm{v}$ ). Sobre a extraordinária figura de médico português e europeu, do séc. XVI, que foi Amato Lusitano, bem como sobre os outros médicos neste passo referidos por Albornoz, vd. Homenagem ao Doutor João Rodrigues de Castelo Branco (Amato Lusitano), Imprensa de Coimbra, 1955. Sobre Manuel Brudo e Dionisio, seu pai, físico de D. João III e professor de Medicina, vd. também BARBoSA MACHADO, Biblioteca Lusitana, III, pp. 199-200. A fama alcançada nas terras de acolhimento por estes médicos justifica que Albornoz, falando de judeus saídos de Portugal, cite apenas médicos... Mas talvez isso se deva ao facto de ter colhido informações sobre eles na obra de André Laguna, distinto médico espanhol que em tempos foi condiscípulo de Amato Lusitano em Salamanca. 
antecipa-se: é verdade que muitos deles descendem de castelhanos que foram desterrados de Castela, mas também é verdade que lá não lhes foi permitido fazer às claras o que em Portugal fazem encapotadamente. De resto, Albornoz entendia que aqueles judeus expulsos, enquanto foram castelhanos, eram moralmente bons, mas agora, feitos cristãos e não querendo continuar a sê-lo, eram ruins (fol. $54 \mathrm{v}$ ).

A carta termina abruptamente aqui, com a indicação de "esta imperfecta", num dos manuscritos.

\section{CONCLUSÃO}

O interesse desta carta de Albornoz reside, antes de mais, no facto de se tratar da única resposta que a Carta a Bartolomeu de Quevedo, de Resende, obteve do lado espanhol, com a particularidade de não ser geralmente referida, quer aqui quer no país vizinho. Perante os dados de que dispomos, não é possível explicar cabalmente um tal silêncio. Mas é provável que, tendo ficado inédita, os espanhóis, a quem mais interessaria divulgá-la, só a tenham conhecido demasiado tarde, quando as circunstâncias políticas the retiraram todo o impacto, isto é, depois da perda da independência de Portugal. Cessados os medos, as rivalidades o os ressentimentos, a carta perdeu razão de ser. Além disso, embora critique Resende por apresentar os argumentos e as conclusões (ou as 'reconstruções') que lhe interessam, Albornoz cai no mesmo defeito. Com uma agravante: um leit-motiv percorre toda a carta e representa o real objectivo dela: dessacralizar Resende (que muitos espanhóis admiraram) e denegrir Portugal, numa toada persistentemente sarcástica e vexatória. Deste modo, a carta transformou-se num violento pasquim, e já nada tem a ver com a serena ironia, ou os brandos costumes, de Resende. Talvez por isso tenha perdido credibilidade.

Seja como for, tanto a carta de Resende como a, resposta virulenta da Albornoz vêm confirmar o acerto das palavras de Ferguson, que Martim de Albuquerque regista deste modo: "Os humanistas, conforme a sugestiva e incisiva fórmula de Ferguson, olhavam a história através das lentes astigmáticas da sua consciência nacional. ${ }^{33}$

Talvez resida ai, na influência das suas lentes deformadores, a incapacidade de que Albornoz deu provas, ao não compreender como é que, contra

\footnotetext{
${ }^{33}$ Vd. MARTIM DE AlbuQUerQue. op. cit., n. 22, pp. 273-274.
} 
ventos e marés, Portugal conseguia fazer-se notar no mundo de então, apesar de tudo. Como confessava, mesmo sem querer:

Offresco al demonio tan malos y perversos ingenios [refere-se aos judeus que saíram de Portugal] y tierra que tal fructo lleva, no se como puede alzar la cabeza para ser vista entre otras naciones (fol. $54 \mathrm{v})$.

Assim se viam castelhanos e portugueses nos recuados e dificeis tempos de $1571 \ldots$

E no entanto, pese embora uma latente ou manifesta desconfiança, ${ }^{34}$ nunca se obnubilou em ambos os povos a consciência da sua proximidade cultural e de interesses, do espaço peninsular que partilham, do grande tronco histórico que lhes é comum, das dificuldades (as mesmas) que tiveram de vencer. Mas, sendo o seu património histórico-cultural inegavelmente comum, não é todavia indistinto, e aí reside, talvez, a fonte desse contraditório e sistemático sentimento de atração e repulsa de que a história das relações entre os dois povos tem, por intermitências, dado testemunho.

${ }^{34}$ R. M. ROSADO FERNANDES entende, contudo, que este sentimento de animosidade e desconfiança entre os dois povos "é mais verificável no comportamento popular do que na atitude da corte e dos próprios intelectuais" ("Raízes do nacionalismo português", op. cit, p. 303). 